\title{
EL ENCANTO MEFISTOFÉLICO DE LA DIALÉCTICA
}

\author{
THE MEPHISTOPHELIAN CHARM OF THE DIALECTIC
}

Héctor Ponce Bogino ${ }^{1}$

\begin{abstract}
RESUMEN
Ciertas instituciones, en el Perú, al imponer una finalidad estrictamente operativa, violentan la enseñanza de la literatura y la filosofía, de la ética y la estética, que son disciplinas que afinan nuestros juicios críticos. Las humanidades, por su parte, luchan por subrayar el valor de su complejidad alentando una reflexión que abarque idealmente distintos puntos de vista. En este artículo, la dialéctica será, primero, una estrategia en la búsqueda de acuerdos, y, segundo, una reflexión radical que podría resultar tan corrosiva como la sátira. Al final, sin embargo, se mostrará que con la dialéctica, no obstante, se pueden correr riesgos por imprecisión.
\end{abstract}

\section{PALABRAS CLAVE:}

Dialéctica, acuerdos, reflexión radical, humanidades, sátira.

\begin{abstract}
Certain institutions in Peru, by imposing a strictly operational purpose, impinge on the teaching of literature and philosophy, of ethics and aesthetics, which are disciplines that refine our critical judgments. The humanities, for their part, struggle to highlight the value of its complexity by encouraging a reflection that ideally encompasses different viewpoints. In this article, the dialectic will be, first, a strategy in the search of agreements, and second, a radical reflection that can be as corrosive as the satire. Finally, however, it will be showed that with the dialectic, one can run the risk of imprecision.
\end{abstract}

\section{KEYWORDS:}

Dialectic, agreements, radical reflection, humanities, satire.

* Docente de la Universidad Femenina del Sagrado Corazón: heaponce@yahoo.es 
Milan Kundera, en su novela La insoportable levedad del ser, muestra que el ser humano, por lo menos en algún momento de su existencia, debería plantearse la disyuntiva entre la levedad o el peso. Este dilema compromete el estilo de vida, y tanto la levedad como el peso cuentan con razones a favor y razones en contra, y, por eso, quien decide elegir conscientemente entre ellas se encuentra en una ardua tarea. Veamos cuáles son los dos cuernos de este dilema. Si se eligiera la levedad, entonces el mundo social y sus circunstancias deben interpretarse como fugaces, una arenilla que el viento sopla y mueve a su antojo, y, como describe Sloterdijh en su Crítica a la razón cínica (2003), se puede ejercer una filantropía cómoda y burguesa, una ayuda social tapándose las narices frente a los pobres, sin perder el ánimo ligero. Desde la levedad se podría -sin exigir explicaciones existenciales o transformaciones éticasevadir el sufrimiento al constatar el nacimiento de niños con enfermedades congénitas, o por poner otro ejemplo, tolerar el círculo infernal de pobreza en el que están atadas generaciones de familias, y muchas otras delicias por el estilo. Pero, esa levedad no dejaría de ser insoportable a causa, precisamente, de la indiferencia y apatía con la que "el leve" valora todo aquello que corre por la vida: es la levedad entendida como una cosmovisión de la insignificancia y de la impotencia propia y ajena.

De otro lado, opuesto a la levedad, está el peso, que sería la forma de vida de quien asume que toda biografía, tanto la ajena como la propia, está constituida por cada día, hora e instante, $\mathrm{y}$ que las acciones que realizamos $\mathrm{u}$ omitimos, lejos de ser imperceptibles, son consubstanciales al mundo social. Es en el peso en que se alineaba JeanPaul Sartre (1999) cuando planteaba que todo individuo tiene efectos sobre la sociedad y es responsable de ella, y, para mostrar que el proceder individual compromete a la humanidad entera, presentaba dos ejemplos. Si soy obrero y me adhiero a un sindicato cristiano en lugar de ser comunista, entonces le trasmito a la humanidad que la supuesta resignación católica es la solución. Si estoy enamorado y quiero casarme, con tal acción no sólo me encamino yo, sino que también contagio a la humanidad en la creencia de la caramelizada vida conyugal. La idea de Sartre es que cuando un individuo elige un estilo de vida, también está creando un modelo, para bien o para mal, en la sociedad. El peso como estilo de vida en la que el valor va de la mano con la entrega y compromiso, que, lejos de aquella arenilla que el viento zarandea a su antojo, es una piedra en la que se talla permanentemente, según Kundera, es la forma de vida que eligió el genio de Beethoven. Pero, pregunta Kundera, con qué seguridad eligió Beethoven la pesadez.

¿Cómo podía saberlo? ¿Cómo podía comprobarlo? Cualquier colegial puede hacer experimentos durante la clase de física y comprobar si determinada hipótesis científica es cierta. Pero el hombre, dado que vive sólo una vida, nunca tiene la posibilidad de comprobar una hipótesis mediante un experimento y por eso nunca llega a averiguar si debía haber prestado oído a su sentimiento o no (Kundera, 1999, p. 41$)$.

Desde luego, Beethoven eligió el peso pero no por cálculos ni por poner en la balanza costos y beneficios ni tomando un 'riesgo seguro'; apostó por la carga más pesada porque buscaba una vida menos vacía, una vida en la que estaba clavado, como Jesús en la cruz, en sus 
propias acciones ${ }^{1}$. El dilema inscrito en la pregunta sobre la pesadez o la levedad es un ejemplo de situaciones en las que el individuo está arrojado a elegir sin el auxilio de manuales preestablecidos. Y parece necesario recordarlo en el seno de una sociedad que, al encontrarse con problemas que merecen una resolución de largo alcance y con matices, sólo ejecuta la salida ofrecida por el hombre de negocios y funcionarios, por el punto de vista que analiza, exclusivamente, el costo-beneficio económico, que es la solución de esos nuevos diosecillos llamados tecnócratas. Sin embargo, varias veces, además de la visión operativa, lo que es oportuno son propuestas que abarquen distintos puntos de vista, y para ello se puede ver a la dialéctica como una forma de razonamiento práctico. Hay que tener en cuenta, además, que la distinción no se presenta entre "ciencias naturales" y "ciencias humanas" (dicotomía relativizada por Thomas Kuhn (1962)), sino entre el "método operativo" y el "proceso dialéctico". Un "método operativo" sería el instrumento del tecnócrata presente en el Perú actual -según la historiadora Cecilia Méndez hoy nos encontramos en una República Empresarial nacida en la dictadura de Fujimori- y presente también, siguiendo al sociólogo Pierre Bordieu, en gran parte del mundo sometido a un "capitalismo de casino" ${ }^{2}$.

La dialéctica trata de comprender un fenómeno sin caer en un reduccionismo, lo que significa que si se investiga un problema que implica que dos puntos de vista se enfrenten, por ejemplo, uno por defender lo sagrado de un apu, y el otro por señalar lo secular de un cerro, en lugar de sólo aceptar el criterio costobeneficio, la dialéctica tomaría en cuenta, además, otras circunstancias, como las intenciones de los involucrados, las cosmovisiones desde las cuales se evalúa la situación en cuestión, y, si fuese el caso, la finalidad social.

Eso es lo que sucede cuando, en líneas generales, en lugar de ver sólo el árbol vemos también el bosque, y es que, siendo necesario el punto de vista técnico, muchas veces no es suficiente. Piénsese en qué sucede cuando nos embarcamos en la lectura de una novela; podemos analizarla, anotar y separar los hechos, las descripciones, los diálogos y las tensiones, punto por punto, y, sin embargo, la suma de las partes analizadas jamás es igual, ni remotamente, a la totalidad de la novela, y a la comprensión de esa totalidad es a la que aspira la dialéctica. ¿Cómo se lograría tan preciado resultado? ¿Cuál es la manera de obtener un conocimiento especializado sin perder la visión panorámica?

La mejor versión de la dialéctica es aquella que no ve al análisis como su opuesto sino aquella que se asume como su complemento, y logra así evitar, en los aspectos estéticos, éticos y científicos, cualquier enfoque monocular sobre las acciones humanas. Ésta es la idea que parece seguir la escuela de la gestalt cuando señala que, en distintas ocasiones -como se puede apreciar con los ejemplos del cubo

1 La cita literal de Kundera dice: "estamos clavados a la eternidad como Jesucristo a la cruz. La imagen es terrible. En el mundo del eterno retorno descansa sobre cada gesto el peso de una insoportable responsabilidad. Ese es el motivo por el cual Nietzsche llamó a la idea del eterno retorno la carga más pesada". Op. cit., p. 12.

2 Desde un punto de vista filosófico, son autores como Dilthey, Husserl, Gadamer, Habermas, entre otros, quienes señalan que en el ámbito del conocimiento se han ido eclipsando áreas como la ética y la estética, y se privilegia a la ciencia sólo en tanto mantenga una función técnica. 
de Necker o el jarrón de Rubin, y con mayor evidencia cuando se aprecia una composición musical- reducir lo que se investiga sólo a sus partes elementales a veces no es una inteligente estrategia. Al analizar, por ejemplo, una obra musical y descomponer el todo en sus partes primordiales, se tendría entre las manos el descompuesto, o sea, las notas musicales separadas entre sí, y cada nota a su vez descompuesta en partículas de corpúsculos, y cada partícula en átomos de moléculas, y así hacia una estela infinitesimal, llegando a un enjambre en el que se encontraría un núcleo denso, indivisible, pero -puesta de nuevo la lupa- adentro habrían más enjambres de enjambres. Este adentrarse hasta mineralizar, por ejemplo, una composición musical corre el riesgo de definir a Fidelio sólo como una sensación producida en el oído por el movimiento de corpúsculos, trasmitidos por un medio elástico, como el aire. El crítico literario y filósofo Walter Benjamin comparó una anti-parábola de Kafka, La muralla china, con un texto de Eddintong, astrofísico que al intentar unificar la mecánica cuántica y la teoría de la relatividad, afirmó: "La parte introductoria de una teoría es la más difícil, ahí tenemos que usar constantemente el cerebro; después, las matemáticas". El texto de Eddington pudo ser titulado "es más fácil que un camello pase por el ojo de una aguja que un físico traspase el umbral de una puerta".

Estoy en el umbral de la puerta, a punto de entrar en mi cuarto, lo cual es una empresa complicada. En primer lugar tengo que luchar contra la atmósfera que pesa con una fuerza de un kilogramo sobre cada centímetro de mi cuerpo. Además debo procurar aterrizar en una tabla que gira alrededor del sol con una velocidad de 30 kilómetros por segundo; sólo un retraso de una fracción de segundo y la tabla se habrá alejado millas. Y semejante obra de arte debe ser llevada a cabo mientras estoy colgado, en un planeta en forma de bola, con la cabeza hacia fuera, hacia el espacio, a la par que por todos los poros de mi cuerpo sopla un viento etéreo a Dios sabe cuánta velocidad. Tampoco la tabla tiene una sustancia firme. Pisar sobre ella es como pisar sobre un enjambre de moscas. ¿No acabaré por caerme? No, porque si me atrevo y piso, una de las moscas me alcanzará y me dará un empujón hacia arriba; caigo otra vez y otra vez me empuja hacia arriba y así sucesivamente. Puedo por tanto esperar que el resultado total sea $\mathrm{mi}$ permanencia siempre aproximadamente a la misma altura. Pero si por desgracia y a pesar de todo cayese al suelo o fuese empujado con tanta fuerza que volase hasta el techo, semejante accidente no sería lesión alguna de las leyes naturales, sino una coincidencia extraordinariamente improbable de cualidades... Cierto es que es más fácil que un camello pase por el ojo de una aguja que un físico traspase el umbral de una puerta. Si se tratase de la boca de un granero o de la torre de una iglesia, tal vez fuera más prudente acomodarse a ser nada más que un hombre corriente, entrando simplemente por ellas, en lugar de esperar a que se hayan resuelto todas las dificultades que van unidas a una entrada por entero libre de objeciones (Benjamin, 1998).

El absurdo descrito por Eddington, el de descomponer por descomponer y de perder de vista la totalidad del mundo circundante, es lo que Hegel -inspirado en el Fausto de Goethe - le criticaba a la filosofía racionalista, prefigurando, así, la idea de que cuando la realidad es analizada desde un exclusivo y excluyente punto de vista, lo que obtenemos es un pálido y fragmentado reflejo de ella. 
La filosofía racionalista -señalaba Hegel- se halla en un error si piensa que al analizar los objetos, es decir, al descomponerlos y separarlos, los deja inalterados, pues en realidad lo que hace es convertir lo concreto en abstracto. Por ello ocurre también que lo vivo es aniquilado, pues sólo lo concreto es viviente [...]. En la medida en que el racionalismo permanece en el punto de vista de la separación, cabría aplicarle aquellas palabras del poeta [Goethe]: "tiene las partes en sus manos, y sólo le falta, ipor desgracia!, el lazo espiritual" (Hegel, 1997). ${ }^{3}$

El problema que puede agazaparse en el uso reduccionista y monocular de cualquier análisis exclusivamente técnico es el riesgo de perder ese lazo espiritual, de que se le escape la síntesis de la complejidad de todo aquello que vive, de todo aquello que concierne a las acciones humanas, que no pueden ser comprendidas, en su cabalidad, si sólo se las examinan a través de un único criterio, un único formulario, un único ángulo de ver y evaluar a la realidad. Al adentrarse en la complejidad de lo vital, uno encuentra que las contradicciones de las acciones humanas, con sus expectativas e intrigas, con sus mitos e irracionalidades, empujan por salirse de cualquier esquematismo. Es lo que sucede cuando distintas áreas de la vida humana -como la artística, la ética- sólo son evaluadas a través de los lentes del cálculo, de la razón operativa, y dichos lentes no son hábiles al evaluar esferas culturales en las que la exclusividad de lo cuantificable y lo medible no son pertinentes. Ésta fue una de las batallas que realizó, a inicios del siglo XIX, el Romanticismo con el objetivo de recuperar del olvido -o de la mala feámbitos soberanos como lo irracional, lo emotivo y lo mítico, aunque, se puede observar, el Romanticismo cayó en otro reduccionismo: sólo son válidos los criterios pasionales y son deleznables los racionales.

Uno de los problemas suscitados por el hegemónico punto de vista del tecnócrata es que aísla las partes del todo orgánico sin un plan o proyecto de largo alcance, y esta circunstancia nos puede ayudar a precisar qué es la dialéctica, y para ello centremos el asunto en dos ejes: la dialéctica como la búsqueda de acuerdos y la dialéctica como una reflexión radical.

Si a la visión del tecnócrata le corresponde cuantificar, a la visión que busca integrar le atañe cualificar; una enumera, la otra considera; una no busca consensos y la otra sí. Lo que marca la diferencia entre una y otra es que mientras la forma de operar del técnico

3 Véanse los versos del Fausto de Goethe, en los que Mefistófeles, a la pregunta acerca de qué debe hacer quien quiera conocer la verdad en el cielo y la tierra, se burla de la operación algo mecánica del método analítico: "Le aconsejo [...], querido amigo,/ seguir primero el Curso de Lógica./ Allí le peinarán debidamente el espíritu,/ se lo calzarán en botas de tortura,/ de suerte que se deslice con más tiento/ por el sendero del pensar/ y no se tuerza acá y allá/ y se descarríe./ [... // En realidad, la fábrica de pensamientos/ es como la obra maestra del tejedor:/ a un golpe de pedal se mueven mil hilos,/ suben y bajan las devanaderas,/ corren invisibles los cabos, / y un golpecito solo fragua miles de combinaciones./ Así también el filósofo aparece/ Y nos demuestra cómo se debe proceder:/ lo primero tiene que ser así, lo segundo asá,/ y de ahí se deriva lo tercero y lo cuarto,/ y si no existiera lo primero y lo segundo,/ no tendríamos nunca lo tercero y lo cuarto./ Así lo aprecian los discípulos por doquier,/ pero ninguno ha llegado a ser tejedor./ Quien aspira a conocer y describir algo vivo,/ Busca ante todo desentrañar el espíritu;/ tiene entonces las partes en sus manos/y sólo falta, ipor desgracia!, el lazo espiritual" (Goethe, 1973, tomo III, p. 1323). 
es como la de una máquina objetiva a la que se le introducen premisas que luego expulsa deducciones, en cambio, a la dialéctica le correspondería la imagen de una discusión en la que se presentan diversas premisas, incluso contrarias entre sí, y luego se recogen los consensos y disensos. En este punto, hay que recordar que habrán quienes apuesten por forjar consensos, como Habermas, Rorty, Gadamer, y habrán otros que subrayarán los disensos, ahí Foucault, Lyotard, Derrida. Quien trazó la diferencia entre, por un lado, un razonamiento meramente formal, en el que se aseguraba que los términos tuviesen sólo un significado, y, de otro lado, la dialéctica como diálogo y polisemia en el que los interlocutores, múltiples puntos de vista fue Aristóteles, y de ahí que a la dialéctica se le atribuya ser el arte de razonar -en oposición al formulario-, y de ahí también que Aristóteles dijera que de lo que se trataba, al sumergirse en las preguntas y respuestas que establecen dos interlocutores, era de extraer de lo establecido algo distinto de lo establecido.

De lo dicho se desprende que al comprender los disensos y buscar consensos con el objetivo de crear un proyecto común, una finalidad, un plan, éstos no se encuentran prefabricadamente, sino que son el fruto de una reflexión de raíz, y, en ese sentido, radical, que busca evaluar incluso las convenciones ya asumidas. La idea de este segundo eje que considera a la dialéctica como una reflexión radical, es que en los temas de los que se ocupan las ciencias sociales y humanas, lejos de encontrar hechos neutrales, se encuentran hechos controvertidos que solicitan ser examinados desde distintos ángulos. Así entendida, la dialéctica permitiría ampliar la comprensión del sujeto, pues, al estar éste ubicado necesariamente en una posición inicial, podría romper con esa unilateral forma de ver el mundo y pensar desde la posición contraria. Dicho criterio sería de utilidad al investigar situaciones en las que no existe evidencia para zanjar conflictos, y la dialéctica, en tanto diálogo y deliberación, puede desarrollarse como ampliación de los criterios de los participantes y, además, en tanto comprensión de cada opinión, buscaría encontrar algunos consensos entre las distintas opiniones, y para ello rastrearía los puntos en que los participantes están de acuerdo. En esa ampliación de criterios un caso significativo es la escritura de Freud:

Por una parte las neurosis despliegan curiosas y enormes semejanzas con las grandes producciones sociales del arte, religión y filosofía, pero por otra presentan la apariencia de caricatura de los mismos. [...] La histeria es una caricatura de una creación artística; la neurosis obsesiva, una caricatura de la religión, y las quimeras paranoicas, la caricatura de un sistema filosófico (Jones, 2003, p. 379).

Otro ejemplo de cómo reflexionar dejando la unilateralidad se puede encontrar en el mismo Hegel cuando discurre sobre la filosofía ética que se ejerció durante la Ilustración. Sin lugar a dudas, Hegel celebra que en la modernidad el individuo se desembarace de los argumentos de la autoridad, separe el ámbito religioso del político, no permita que las castas continúen con el poder, y que la consigna medieval de que "la filosofía debía estar al servicio de la fe" sea combatida.

Asimismo, sin embargo, Hegel reflexiona sobre las desventajas de los logros de la Ilustración -sí, porque algo 
debemos de haber perdido con ella-, y entre dichas desventajas encuentra que en la modernidad, a diferencia de lo que sucedía en el Mundo Antiguo y el Mundo Medieval, se ha perdido una armonía. La armonía a la que se refiere es a aquella en la que vivían los griegos al participar en grandes proyectos colectivos que los hermanaban y en ideales sociales comunes, y que lamentablemente el sujeto moderno ha perdido a causa de la separación, necesaria, entre el ámbito público y el ámbito privado ${ }^{4}$. Expuesto así, pareciera que Hegel debiera tomar una posición al respecto: o continúa con los ideales de la modernidad o persigue la nostalgia del mundo greco-romano. ¿Qué posición toma Hegel? Buscaba conciliar ambos ideales en una síntesis que no se detendría nunca, sino que $-\mathrm{y}$ eso sería reflexionar- a veces se "flexiona" hacia un opuesto y otras veces se "flexiona" hacia el otro, y esa flexibilidad es el ideal de la dialéctica que busca disolver planteamientos que poseen la forma de "o este bando o este otro", pues no hay ninguna solución ahí cuando solamente se cambia un dogma por otro.

Presentada así, la dialéctica sería una forma radical de reflexionar que permitiría al intelectual tomar distancia de la posición en la que empezó su investigación. Al tomar conciencia de que el punto de vista propio era tan sólo una posición inicial, que merecía ser cuestionada, entonces se caería en la cuenta de que había excluido otras perspectivas y ampliaría así su etnocentrismo. Esto fue lo que quiso mostrar Hegel con la imagen del tránsito que todo ciudadano realiza desde la familia a la sociedad civil. "Hay un brusco y aun violento repudio a los confortables valores del hogar, un rechazo a todo lo que precisamente hace atractivo el hogar. La soledad, el riesgo y la aventura magnetizan el alma del adolescente que comienza su camino hacia afuera, hacia la sociedad civil, que es el ámbito de los extraños" (Scruton, 1994, p. 463). Ese periplo, en la medida en que se aleja de la posición inicial, irá incubando una intensa nostalgia por el hogar, y, en un determinado punto, el trayecto del viaje se convertirá en retorno al lugar desde el que se empezó, y una vez ahí se vería por primera vez al hogar. Desde este segundo eje, la dialéctica sería una estrategia para resaltar lo ingenuo y lo unilateral de las propias concepciones, y, así, considerar, por lo menos de manera inicial, que el punto de vista opuesto pudiese poseer algún sentido.

Gadamer (1994), quien se ha ocupado del tema, señala que la dialéctica no es un método para predecir el futuro -como pensaron erradamente Hegel y Marx-, sino el arte de razonar y de ampliar la visión unilateral de las ideologías, y la clave estaría en comenzar por la ideología que carga cada uno, pues tal como lo presentó Ortega y Gasset (1958, p.14), "el suspicaz se engaña a sí mismo creyendo que puede eliminar su propia ingenuidad".

Pensar de esta manera alejaría al individuo de las visiones dogmáticas y mostraría de qué trata la conciencia histórica que Hegel plantea en una célebre frase: "la filosofía es su época captada en pensamientos" (1975, p. 24). La conciencia histórica aplasta al ingenuo que cree que su opinión actual es soberana sobre las del pasado y que en el futuro no cambiará, y muestra la patética mueca de los grupos fanáticos

4 Charles Taylor, siguiendo la crítica de Hegel, plantea que con la modernidad hemos perdido una dimensión heroica de la vida. "La gente ya no tiene la sensación de contar con un fin más elevado, con algo por lo que vale la pena morir. [...] Sufrimos por falta de pasión". (Taylor, 1994, p. 39). 
por evitar ser un punto de vista más entre otros.

Un corrosivo contra los dogmáticos es también la sátira, y en ella Gadamer encuentra similitudes con la dialéctica: en ambas se busca explorar cuáles podrían ser los resultados del juego de ir zurciendo diversas perspectivas y situaciones contrarias. En su movimiento lúdico, la sátira muestra el mundo en su versión invertida, colocado de cabeza, y honra lo que en el Mundo Usual es despreciado, y desprecia lo que en éste es honrado.

El mundo invertido no es simplemente lo contrario, el mero y abstracto opuesto del mundo existente. Lo que hace esta reversión, en la que todo cobra otro cariz, es precisamente hacer visible, en una especie de espejo desfigurador, la secreta inversión de cuanto hay a nuestro alrededor. Ser el 'mundo invertido' de la inversión del mundo significa exponer a contrario lo inverso (Gadamer, 1994, p. 68).

Lo que puede lograr este espejo con sus desfiguraciones es reordenar aquello que se valora como positivo y negativo, y revelarnos de ese modo la hipocresía moral de las sociedades. Desde luego, una visión fanática del mundo necesariamente debe repudiar a la sátira, y esa intolerancia se encuentra retratada por Umberto Eco en El nombre de la rosa en el momento en el que uno de los religiosos principales de la abadía explica por qué aborrece la risa:

La risa libera al aldeano del miedo al diablo, porque en la fiesta de los tontos también el diablo parece pobre y tonto, y por tanto, controlable. Pero este libro podría enseñar que liberarse del miedo al diablo es un acto de sabiduría. Cuando ríe, mientras el vino gorgotea en su garganta, el aldeano se siente amo porque ha invertido las relaciones de dominación [...]. La risa distrae, por algunos instantes, al aldeano del miedo. Pero la ley se impone a través del miedo, cuyo verdadero nombre es temor de Dios. [...] Y la risa sería el nuevo arte, ignorado incluso por Prometeo, capaz de aniquilar el miedo. [...] Y este libro, que presenta como milagrosa medicina a la comedia, a la sátira y al mimo, afirmando que pueden producir la purificación de las pasiones a través de la representación del defecto, del vicio, de la debilidad, induciría a los falsos sabios a tratar de redimir (diabólica inversión) lo alto a través de la aceptación de lo bajo. Pero si algún día [se] justificasen los juegos marginales de la imaginación desordenada, ioh, entonces sí que lo que está en el margen saltaría al centro, y el centro desaparecería por completo. [...] Pero si algún día alguien [...] elevase el arte de la risa al rango de arma sutil, si la retórica de la convicción es reemplazada por la retórica de la irrisión [...], ioh, ese día también tú [...] y todo tu saber, quedaríais destruidos! [...] Si algún día [...] el arte de la irrisión llegase a ser aceptable [...], si algún día alguien pudiese decir (y ser escuchado): "Me río de la Encarnación...". Entonces no tendríamos armas para detener la blasfemia, porque apelaría a las fuerzas oscuras de la materia corporal, las que se afirman en el pedo y en el eructo [...] (Eco, 2005, pp. 681-685).

Uno de los aciertos literarios del fragmento de Eco se encuentra en el 
contrapunto que tiene dejar que el enemigo de la sátira sea quien hable de ella, y así logra que el lector recuerde por qué es odiada, sin necesidad de hacer una apología de ella. La clave del contrapunto consiste -como señala Richard Rorty- en que hay más probabilidades de advertir los sufrimientos de una persona si llama nuestra atención la indiferencia con la que es observada por otra persona. Lo que hace visible la miseria del campesinado es el dispendio ostensible de la nobleza, y lo que hace visibles las chozas de los negros son las ostentosas mansiones de los blancos. "La observación de Hegel era justa: no advertiremos la tesis [...] a no ser que capte el reflejo, el fuego mortecino, de una flamante, brillante antítesis" (Rorty, 1991, p. 183). En esa búsqueda por un estilo que muestre distintos contrastes, Rorty confiesa que su escritura apela a la redescripción, a enfrentar léxicos distintos entre sí, y no tanto a inferir proposiciones. En el artículo "Ironía privada y esperanza liberal", Rorty se explaya sobre el tema.

Pienso que la Fenomenología de Hegel es tanto el comienzo del fin de la tradición platónico-kantiana como el paradigma de la capacidad del ironista de explotar las posibilidades de una redescripción abundante. Según esta forma de ver, el llamado método dialéctico de Hegel no es un procedimiento argumentativo o una forma de unir sujeto y objeto, sino simplemente una técnica literaria: la técnica de producir cambios sorpresivos de configuraciones mediante transiciones suaves y rápidas de una terminología a otra.

En lugar de conservar las viejas trivialidades y elaborar distinciones que ayuden a darles coherencia, Hegel modifica constantemente el léxico en el cual se han formado las viejas trivialidades; en lugar de construir teorías filosóficas y de argumentar en su favor, elude la argumentación cambiando constantemente de léxico y cambiando con ello de tema. En la práctica, aunque no en la teoría, eliminó la idea de llegar a la verdad a favor de la idea de hacer cosas nuevas. La crítica que hace a sus predecesores no es que sus proposiciones fuesen falsas, sino que sus lenguajes eran obsoletos. Al inventar esa forma de crítica, el joven Hegel se zafó de la secuencia Platón-Kant e inició una tradición de filosofía ironista que se continúa en Nietzsche, Heidegger y Derrida (Rorty, 1991, p. 96).

Resulta pertinente recordar que un buen número de órdenes medievales consideró que la dialéctica descarriaba a los hombres del camino correcto, $\mathrm{y}$, siendo misóginas algunas órdenes de la iglesia medieval -tan sólo en las cacerías de brujas la Iglesia Católica asesinó a nueve millones de mujeres-, se personificó a la dialéctica como una mujer que, por su rostro pálido, debía de pasar mucho tiempo en las bibliotecas, por sus cabellos rojos y alborotados debía de tener ideas amenazantes, y que, en el colmo de los males, en una mano llevaba un libro y en la otra, un escorpión ${ }^{5}$; razón por la que se puede decir que se condenaba a la dialéctica por ser lectora, imaginativa y contestataria.

Finalmente, este artículo no sería dialéctico si no hiciera una crítica a la misma dialéctica y dejase pasar la pregunta sobre qué sucedería si se le quita ese encanto mefistofélico,

5 Quien dude del odio hacia la mujer por parte de algunas autoridades de la Iglesia Medieval, puede revisar, entre otros textos, el Málleus Maleficarum (El martillo de las brujas), libro en el que, bajo la aprobación oficial de los doctores de la Facultad de Teología de Colonia, y del Papa, se inició una de las mayores barbaries de la historia contra la mujer. 
ese cautivador aroma a azufre y a transgresión. ¿Qué pasaría, pues, si relativizáramos a la propia dialéctica? Una pregunta semejante se planteó el mismo Hegel, y debió de reír para sus adentros cuando pensó que ése era otro movimiento que ya se encontraba incubado por la propia concepción de la dialéctica.

Dejando al lado ese escollo, que parece más la conjura de un maleficio sobre aquellos que osan lanzar una crítica a la dialéctica, concierne ahora, para ser coherente con lo escrito, tomar distancia de la posición inicial del presente artículo, que era a favor de la dialéctica, y empezar a cuestionarla. A Kant, por ejemplo, y no por las mismas razones que la de los medievales, no le seducía en absoluto la dialéctica. Mucho más cauto que Hegel, pensaba que ella podía degenerar en un uso contradictorio y meramente abstracto de la razón y, por ello, podía enredarse consigo misma. Hegel, en cambio, sosteniendo una tesis metafísica, y con un nuevo sortilegio, rebautizó los peligros que advertía Kant sobre enredarse en contradicciones y los nombró pasos esenciales de la dialéctica, pues la razón operaría, siempre, contraponiendo tesis y antítesis, subsumiéndolas en síntesis.

Quien no le temía a las imprecaciones era Schopenhauer, y para él la dialéctica no era sino charlatanería, un modo de salir victorioso en las disputas verbales a la que no le atribuía ningún valor. Para él la dialéctica sólo era un conjunto de estratagemas para ganar banales discusiones en las que la verdad no era el tema, sino la vanidad de los opositores. Desde luego, él también leyó el Fausto y recogió esta cita: "Con frecuencia creen los hombres, cuando escuchan sólo vacías palabras, que se trata de hondos pensamientos" (Shopenhauer, 2005, p. 63).
Con ello quería denunciar a los 'diablillos dialécticos' que, habituados a escuchar, arrobados, cosas que no comprenden, se le puede hacer creer cualquier desatino siempre y cuando se les hable con aire docto y profundo. Schopenhauer se refería directamente a Hegel, y le dedicó este delicioso fragmento:

La mente condenada a leer la Hegel] espera en vano toparse con pensamientos verdaderos, sólidos y sustanciales; languidece y añora la aparición de una idea cualquiera, como el viajero del desierto arábigo añora el agua... hasta que al final muere de sed (Shopenhauer, 2006, p. 64).

Una valoración provisional sobre el tema sería la de ver que cuando una idea se presenta en su versión minimalista, sin ambiciones estrafalarias, convence más que en su versión inflada y pomposa, y eso se cumple con la dialéctica: presentarla como algo más que razonar teniendo presente las premisas contrarias, como algo más que reunir distintos puntos de vista, como algo más que analizar con una finalidad, es un error. En su versión maximalista, apoteósica y metafísica, la dialéctica resulta una telaraña gaseosa de generalidades con la que se pretenden extraer -como ironizaba Karl Popper (2006, p. 244) "conejitos físicos de galeras puramente metafísicas".

Una buena parte de ese error es causado por quienes usan a la dialéctica como un recetario de mantras y pócimas y escriben extrañas ideaciones, y fue lo que combatió Theodor Adorno (2005) cuando escribió Dialéctica negativa. Marco Aurelio Denegri (2008) cuenta un relato persa que en Ispahán, se encontraron un alcohólico, un opiómano y un consumidor de hachís en frente de una cantina que, de noche, tenía cerrada la puerta. 
Sin ideas, el alcohólico, vehemente, quiso tumbar a patadas la puerta; el opiómano, resignado, se recostó en ella; sólo el consumidor de hachís tuvo una ocurrencia: ¿y si pasamos por el ojo de la cerradura?

Una ingeniosa idea, sí, pero sólo eso. El riesgo de la miopía del tecnócrata llevaría a la solución del alcohólico, y no solo tumbaría la puerta sino que, con nitroglicerina, volaría en mil pedazos toda la cantina; pero el riesgo del dialéctico radica en las otras dos figuras. Como el opiómano es el apocalíptico que espera que algún día las soluciones lluevan del cielo y que Dios Padre haga justicia, y como el consumidor de hachís es el iluminado por ingeniosas ideaciones, pero quizás de inusual valor práctico.

Estas ideas podrían desalentar al lector que busca una metodología segura que lo blinde de la intemperie de la ambigüedad y que lo proteja de la ambivalencia. Ese lector desea no reflexionar. En la línea de no rehuir de la ambigüedad y de la polisemia, Vicente Santuc recordaba -a propósito de Hegelque las estrategias argumentativas usadas por un sofista para confundir son las mismas llaves usadas por un filósofo honrado.

No existen formas verbales y gramaticales que permitan diferenciar las mañas y el ardid del sofista que juega con sofismas, de la verdadera búsqueda del dialéctico apasionado por la verdad. [...] Era para evitar esas trampas que Sócrates procuró ceñirse a la mera lógica. Pero como lo nota Aristóteles el sofisma no sale de la lógica: juega con ella.

Pienso en la figura del "abogado del diablo", personaje que la Iglesia solicita antes de declarar solemnemente santo a alguien y que se ocupa de dar razones y evidencias en contra de la canonización de algún beato. Y recuerdo el cuento del irónico de Apollinaire, Le sacrilège (2003), en el que se relata cómo Roma encarga ser abogado del diablo al padre Serafín, quien, al tomar demasiado en serio dicho rol, logró que no se canonizara a nadie e, incluso, espolvoreó sobre los santos ya consagrados la duda siniestra de que si él hubiese desempeñado el oficio en la época de aquellas canonizaciones, la hagiografía sería distinta o despoblada.

Si se buscara el mejor sentido de la dialéctica, ese sería el de aquel que la asocia al sobrio razonamiento ético. Pero, el intelectual de las ciencias sociales y humanas, muchas veces, no se encuentra tentado por la precisión y la parquedad, sino por la frondosidad y la verborrea, y por ello suele creer, como cree el hechizado por la peor dialéctica, que ella, por arte de magia, lo puede todo. En fin, sólo cabe tener presente que, en su peor versión, el dialéctico corre el riesgo de convertirse en la fusión del apóstol Juan, el brujo Merlín y Mandrake el mago.

\section{REFERENCIAS:}

ADORNO, T. (2005) Dialéctica negativa y la Jerga de la autenticidad. Traducción de Alfredo Brotons. Madrid: Akal.

APOLLINAIRE, G. (2003) Relatos perversos: el heresiarca y cía. Traducción de Alberto Laurent. Barcelona: Ediciones Abraxas.

BENJAMIN, W. (1998) Imaginación y sociedad. Iluminaciones I. Traducción de Jesús Aguirre. Buenos Aires: Alfaguara.

DENEGRI, M. A. (2008) Hechos y opiniones acerca de la mujer. Lima: 
Universidad Nacional Mayor de San Marcos.

ECO, U. (2005) El nombre de la rosa. Traducción de Ricardo Pochtar. Barcelona: Lumen.

GADAMER, H. G. (1994) La dialéctica de Hegel. Cinco ensayos hermenéuticos". Traducción de Manuel Garrido. Madrid: Ediciones Cátedra.

GOETHE, J. W. (1973) Fausto.Traducción de Rafael Cansinos Assens. Tomo III, p. 1323. Madrid: Aguilar.

HEGEL, G. W. F. (1997) Enciclopedia de las ciencias filosóficas. Traducción de Ramón Valls Plana. Madrid: Alianza Editorial.

HEGEL, G. W. F. (1975) Principios de la filosofía del derecho. Traducción de Juan Luis Vermal, Buenos Aires: Sudamericana.

JONES, E. (2003) Vida y obra de Sigmund Freud. Traducción de Mario Carlisky y José Cano Tembleque. Barcelona: Anagrama.

KUHN, T. (1962) The Structure of Scientific Revolutions. Chicago: University of Chicago Press.

KUNDERA, M. (1999) La insoportable levedad del ser. Traducción de Fernando. Barcelona: Tusquets Editores.
ORTEGA Y GASSET, J. (1958) Kant, Hegel y Dilthey. Madrid: Revista de Occidente.

POPPER, K. (2006) La sociedad abierta y sus enemigos. Traducción de Eduardo Loedel. Barcelona: Paidós.

RORTY, R. (1991) Contingencia, ironía y solidaridad. Traducción de Alfredo Sinnot. Barcelona: Paidós.

SARTRE, J. P. (1999) El existencialismo es un humanismo. Traducción de Victoria Praci de Fernández. Barcelona: Edhasa.

SCHOPENHAUER, A. (2005) El arte de tener razón. Traducción y estudio de Dionisio Garzón. Madrid: Edaf.

SCHOPENHAUER, A. (2006) El arte de insultar. Traducción de Fabio Morales. Madrid: Alianza Editorial.

SCRUTON, R. (1994) Filosofía Moderna. Una introducción sinóptica. Traducción de Héctor Orrego. Santiago de Chile: Cuatro Vientos.

SLOTERDIJH, P. (2003) Crítica de la razón cínica. Madrid: Siruela.

TAYLOR, C. (1994) La ética de la autenticidad. Traducción de Pablo Carbajosa Pérez. Barcelona: Paidós. 